\title{
Will a breast screening programme change the workload and referral practice of general practitioners?
}

\author{
Joy Ashby, Martin Buxton, Hugh Gravelle
}

\begin{abstract}
Study objective-The aim of the study was to consider possible changes in the clinical activities of general practitioners whose patients are registered in a breast cancer screening programme.

Design-The study was a survey based on completion of forms recording breast consultations carried out by participating general practitioners during a four week period.
\end{abstract}

Setting-One of three intervention centres and one of three comparison centres in the national trial of early detection of breast cancer was selected. The intervention centre was in Guildford; the comparison centre in Stoke on Trent.

Participants-The participants were general practitioners in the selected centres. In Guildford, 64 of 99 general practitioners approached took part (65\%); in Stoke on Trent, 81 of 177 took part $(46 \%)$. The proportion of male and female participants in the two centres was similar. Doctors in Stoke on Trent were older and worked in smaller practices than in Guildford.

Results-A comparison of workloads showed that in the screening centre there was less demand for doctor consultations from those in the screened age group, but those excluded from screening made more use of the general practitioners' services. A difference in referral practice was also apparent, with doctors in the screening centre referring more frequently for specialist advice.

Conclusions-The evidence suggests that no significant change in the overall use of general practice resources can be expected with the introduction of national screening, but there may be greater pressure on assessment services.

The Forrest Committee on Breast Cancer Screening recommended the establishment of a national screening programme for women aged between 50 and 65 years. ${ }^{1}$ The report envisages an important role for the general practitioner in the screening programme. The general practitioner will be asked to establish that it is appropriate to call women for screening from the lists provided by Family Practitioner Committees and to be the signatory to the letters of invitation to be sent to each woman. Women outside the invited age group for screening will be advised to consult their general practitioner, who may refer them to the screening service if the woman is considered at increased risk. The doctor may take the decision on referral for assessment when an abnormality is detected and will have a number of tasks concerned with monitoring and follow up of women at all stages.

These responsibilities will use the resources of general practitioners and their surgeries. However, if doctors choose to allow direct referral of their patients from screening to the specialist assessment teams, they need not, in theory, be directly involved in the clinical care of breast cases in the screened age group. It might therefore be argued that the breast workload of such general practitioners would be reduced. There is little information about the effects of screening or other interventions on general practice. In a survey of GPs in Edinburgh, $53 \%$ of respondents had the impression that breast consultations had increased in the five previous years, for three of which there had been a screening programme; only $31 \%$ of GPs surveyed in Oxford, where there was no screening, liad the same impression. ${ }^{2}$

The Southampton breast study concluded that a short intensive health education campaign about breast care was unlikely to increase GP workload. ${ }^{3}$ Bywaters found a dramatic peak in consultations in Birmingham coinciding with publicity about the mastectomies of Mrs Ford and Mrs. Rockefeller. ${ }^{4}$ In Daventry, Adam (unpublished data) found a slight but statistically insignificant increased consultation rate from women with minor breast problems during a health education programme about breast disease and self examination. There was some indication of a change in referral practice, with a higher proportion of women referred to hospital during than before the intervention.

As part of an economic evaluation of the early detection of breast cancer we investigated the differences in GP breast workload in an area with a population screening programme and an area with no screening. The aims of this study were to discover if there was a difference between the areas and, if so, whether it could be attributed to the screening programme.

\section{Methods}

Six English centres have taken part in the national trial of early detection of breast cancer. ${ }^{5}$ Three intervention centres offered an early detection service for women aged 45 years and over and three comparison centres followed a conventional management strategy with no early detection services. One of each group was selected for this study. The lists of general practitioners with patients registered in the trial were obtained from the trial centres. In the comparison centre, Stoke on Trent, each doctor was asked by post to take part in the study. The screening centre selected 
was Guildford, where every two years women were offered a clinical examination by a doctor plus a mammogram. Those who accepted the invitation were also offered a clinical examination in the next year.

An introductory letter was sent and one of the research team (JA) visited the majority of practices. The doctors in both centres were asked to keep a simple one line record, on forms provided, of each breast consultation during a four week period. Information was recorded on date of consultation, age of woman, type of visit (whether new or follow up, for symptoms, screening or some other reason), procedures conducted during the consultation, action taken as a result (eg, referral to a consultant, prescription of drugs), provisional diagnosis and any pertinent comments. The four week periods were in February 1986 in Stoke, and in March or April 1986 in Guildford. Monitoring of media cc erage of breast health during this time revealed no major items which might have caused the level of consultations to vary during the period of data collection.

\section{Results}

\section{RESPONSE RATES}

A higher rate of response was achieved from general practitioners in Guildford. This is attributed to the personal request for cooperation, and the greater interest in breast health because of the screening programme. In Guildford $64(65 \%)$ of the 99 general practitioners approached took part in the study, as against $81(46 \%)$ of the 177 general practitioners in Stoke. The proportions of male and female participants were similar in the two centres. There were differences in the distribution of age and practice size, with the doctors in Stoke being older and working in smaller practices than in Guildford.

\section{CONSULTATION RATES}

A total of 298 consultations were reported in Guildford, and 375 in Stoke. The mean rates of consultations per general practitioner over four weeks were 4.66 and 4.63 . The median rates were 4 in Guildford and 3 in Stoke. A $t$ test $(p=0.975)$ and a median test $(p=0.363)$ indicated that the consultation rates were not significantly different. Consultation rates per 1000 women at risk (using average list size and proportions of females in the populations for the South West Surrey and North Staffordshire health authorities) were 4.2 per 1000 in Guildford and 4.3 per 1000 in Stoke. Again the difference between these rates was not significant.

The consultations were concentrated amongst a smaller proportion of doctors in Stoke, where $32 \%$ of respondents had no breast consultations

Table I Age distribution of women consulting from Stoke and Guildford and women in the population of North Staffordshire and South West Surrey Health Authorities (HA)

\begin{tabular}{|c|c|c|c|c|}
\hline $\begin{array}{l}\text { Age group } \\
\text { (years) }\end{array}$ & $\begin{array}{l}\text { Stoke sample } \\
(\mathrm{n}=371) \%\end{array}$ & $\begin{array}{l}\text { North Staff HA } \\
\text { population } \\
(\mathbf{n}=234 \text { 752) \% }\end{array}$ & $\begin{array}{l}\text { Guildford Sample } \\
(n=298) \%\end{array}$ & $\begin{array}{l}\text { S W Surrey HA } \\
\text { population } \\
(\mathrm{n}=94 \mathrm{725}) \%\end{array}$ \\
\hline $\begin{array}{r}0-24 \\
25-34 \\
35-44 \\
45-54 \\
55-64 \\
65+ \\
0-44 \\
45+\end{array}$ & $\begin{array}{r}13 \cdot 7 \\
27 \cdot 3 \\
23 \cdot 4 \\
17 \cdot 8 \\
9.4 \\
8 \cdot 4 \\
64 \cdot 4 \\
35.6\end{array}$ & $\begin{array}{l}32.6 \\
13.3 \\
13.2 \\
10.9 \\
11.6 \\
18.3 \\
59.2 \\
40.8\end{array}$ & $\begin{array}{r}17 \cdot 1 \\
29 \cdot 9 \\
25 \cdot 8 \\
12 \cdot 8 \\
8 \cdot 0 \\
6 \cdot 4 \\
72 \cdot 8 \\
27 \cdot 2\end{array}$ & $\begin{array}{l}31.8 \\
12.9 \\
13.5 \\
11.0 \\
11.1 \\
19.7 \\
58.2 \\
41.8\end{array}$ \\
\hline
\end{tabular}

in the four week period. In Guildford, only $8 \%$ fell into this category.

\section{AGE OF PATIENTS CONSULTING}

Women from a wide age range were seen in both centres. There was a significant difference $\left(\chi^{2}=\right.$ $5.46, p<0.05)$ between the distribution of ages in the two centres, with the doctors in Guildford seeing more women in the younger $(<45$ year) age group (table I). The screening service in Guildford was available to women aged 45 and over. The association between centre and age of women consulting could not be explained by differences in the age distribution of women in the populations of the health authorities. The proportion of women aged less than 45 was $58 \%$ in South West Surrey and $59 \%$ in North Staffordshire (1986 estimates). Guildford doctors reported seeing more women for family planning consultations where a breast examination had been included, but a significant difference in age distribution between the two centres was still found after the exclusion of family planning consultations from the analysis $\left(\chi^{2}=4 \cdot 75\right.$, $\mathrm{p}<0.05)$.

\section{TYPE OF CONSULTATION}

In Guildford, a consultation with a new breast symptom was the most frequent reported; in Stoke there were slightly more consultations for

Table II All breast consultations by type, Stoke and Guildford.

\begin{tabular}{lll}
\hline $\begin{array}{l}\text { Type of } \\
\text { consultation }\end{array}$ & $\begin{array}{l}\text { Stoke } \\
(\mathrm{n}=371)\end{array}$ & $\begin{array}{l}\text { Guildford } \\
(\mathrm{n}=298)\end{array}$ \\
& $0^{\circ}$ & $0_{0}$ \\
\hline Symptoms: new & 31.8 & 37.6 \\
Symptoms: repeat & 19.7 & 19.8 \\
Screening & 32.3 & 18.1 \\
Family Planning & 6.7 & 11.7 \\
Other & 7.5 & $12 \cdot 1$ \\
Unknown & 1.9 & 0.7 \\
\hline
\end{tabular}

screening (table II). The proportions of women consulting with symptoms were different and the difference between the centres was more marked for the over $\mathbf{4 5}$ years age group (table III).

\section{REFERRAL PRACTICE}

The general practitioners reported different patterns of referral practice (table IV). In Guildford $33.9 \%$ of women were referred for specialist advice (including direct referral for mammography) following the consultation. The equivalent figure in Stoke was $\mathbf{1 6 . 7 \%}$. In Stoke more than half $(51.2 \%)$ were reassured and no further action was proposed, and $22.7 \%$ were asked to return to the general practitioner. The proportions in Guildford were $42.0 \%$ and $18.0 \%$ respectively. The contrast is greater when new symptomatic consultations are considered. Table $V$ shows the actions taken for the 96 new cases in Stoke and 82 new cases in Guildford where a provisional diagnosis was made by the general practitioner. Whereas suspected cases of cancer were managed similarly in the two centres, referral for suspected benign disease was more frequent in Guildford than in Stoke $\left(\chi^{2}=7.95\right.$, $\mathrm{p}<0.01$ ). (However, this difference in referral practices may be accounted for in part by the facility, even prior to the trial, for Guildford GPs to refer directly to open access mammography.) 
Table III Symptomatic and screening breast consultations by age group. Values in brackets are percentages.

\begin{tabular}{|c|c|c|c|c|c|c|c|c|c|c|}
\hline \multirow{4}{*}{$\begin{array}{l}\text { Stoke } \\
\text { Guildford }\end{array}$} & \multicolumn{5}{|c|}{ Age $<44$} & \multicolumn{5}{|c|}{ Age 45+ } \\
\hline & \multicolumn{2}{|c|}{ Symptoms } & Screening & \multicolumn{2}{|c|}{ Total } & \multicolumn{2}{|c|}{ Symptoms } & Screening & \multicolumn{2}{|c|}{ Total } \\
\hline & $\begin{array}{l}127 \\
116\end{array}$ & $\begin{array}{l}(64 \cdot 8) \\
(75 \cdot 3)\end{array}$ & $\begin{array}{ll}69 & (35 \cdot 2) \\
38 & (24 \cdot 7)\end{array}$ & $\begin{array}{l}196 \\
154\end{array}$ & $\begin{array}{l}(100) \\
(100)\end{array}$ & $\begin{array}{l}64 \\
55\end{array}$ & $\begin{array}{l}(55.7) \\
(77.5)\end{array}$ & $\begin{array}{ll}51 & (44 \cdot 3) \\
16 & (22.5)\end{array}$ & $\begin{array}{r}115 \\
71\end{array}$ & $\begin{array}{l}(100) \\
(100)\end{array}$ \\
\hline & \multicolumn{5}{|c|}{$\chi^{2}=4.42, p<0.05$} & \multicolumn{3}{|c|}{$\chi^{2}=9.86, p<0.01$} & & \\
\hline
\end{tabular}

\section{Discussion}

Although there were similar overall rates of consultations for breast care in Guildford and Stoke, differences :vere detected in the age of women consulting, the reasons for consultation and the choices made by general practitioners for management of breast disease. Socioeconomic indicators such as proportions of unskilled workers, unemployment rates or car ownership for the two areas suggest a higher status in Guildford than in Stoke. It is generally recognised that health programmes concerned with

\begin{tabular}{|c|c|c|}
\hline & $\begin{array}{l}\text { Guildford } \\
\text { n }(\%)\end{array}$ & $\begin{array}{l}\text { Stoke } \\
\text { n }\end{array}$ \\
\hline $\begin{array}{l}\text { Referred to Consultant } \\
\text { Referred to Screening Centre }\end{array}$ & $\begin{array}{ll}44 & (18 \cdot 0) \\
15 & (6 \cdot 1)\end{array}$ & $46(14 \cdot 2)$ \\
\hline $\begin{array}{l}\text { Reterred directly for } \\
\text { mammography } \\
\text { Subtotal: specialist referrals }\end{array}$ & $\begin{array}{lr}24 & (9 \cdot 8) \\
83 & (33.9)\end{array}$ & $\begin{aligned} 8 & (2 \cdot 5) \\
54 & (16 \cdot 7)\end{aligned}$ \\
\hline $\begin{array}{l}\text { Asked to return to GP } \\
\text { Reassured, no further action } \\
\text { Drugs prescribed }\end{array}$ & $\begin{aligned} 44 & (18.0) \\
102 & (42.0) \\
33 & (13.5)\end{aligned}$ & $\begin{array}{rr}78 & (22 \cdot 7) \\
166 & (51 \cdot 2) \\
46 & (14 \cdot 2)\end{array}$ \\
\hline Total number of actions & 262 & 344 \\
\hline Total number of women & $245(100 \cdot 0)$ & $324(100 \cdot 0)$ \\
\hline
\end{tabular}

education, prevention and early detection are more readily taken up or adhered to by people of higher socioeconomic status. This has been shown generally ${ }^{6}$ and in the field of breast health. ${ }^{78}$ Attitudes to prevention and early diagnosis have also been shown to vary with age of general practitioners. Younger doctors, for example, are more likely to favour regular cervical smear tests. ${ }^{9}$ These factors suggest that in the absence of screening there should be a greater demand for and supply of breast advice and thus a higher consultation rate in Guildford than in Stoke. In fact, general practitioners in Guildford saw a smaller proportion of women from the trial age group (45 and over). Thus the screening service may have led to a reduction in activity in this age group. However, there was a higher proportion of consultations from younger women in Guildford, which suggests that at least a proportion of general practice resources released by the screening programme may have been redirected towards increased breast care for the women excluded from the programme. The Forrest report recommends that in the national screening programme non-invited women should be encouraged to consult their general practitioner. Thus there are unlikely to be any significant resource savings in the general practitioner service as a result of the national screening service.

The difference in management and referral practice in the two centres is striking. The estimated requirements for assessment services in the national programme are based on estimated number of referrals from the trial screening centres. The experience at Guildford suggests that the specialist assessment services will be used by women outside the screened age group. General practitioners may be expected to refer more frequently for specialist assessment, even when they anticipate a benign diagnosis.

We would like to thank the general practitioners who provided information, staff at the trial centres for their support, and Mandi Davies, Mary Elliott and Nicky Gillard for computing and secretarial assistance. This research has been supported by a grant from DHSS.
Table $V$ Provisional diagnosis by action taken, new symptomatic consultations

\begin{tabular}{|c|c|c|c|c|c|c|}
\hline & \multicolumn{5}{|c|}{ Provisional diagnosis } & \multirow[b]{2}{*}{ Total } \\
\hline & Normal & Benign & & Cancer & Non-breast & \\
\hline \multirow{4}{*}{$\begin{array}{l}\text { Total number of women } \\
\text { Action: } \\
\text { Specialist referral` } \\
\text { Return to GP } \\
\text { Reassured, no further } \\
\text { action } \\
\text { Drugs prescribed }\end{array}$} & & $n=60$ & Guildford & $n=9$ & $\mathrm{n}=7$ & $n=82$ \\
\hline & $n=6$ & $\mathrm{n}=60$ & & $n=9$ & $\mathbf{n}=7$ & $\mathrm{n}=82$ \\
\hline & $\begin{array}{l}1 \\
1\end{array}$ & $\begin{array}{l}34 \\
15\end{array}$ & & $\frac{9}{-}$ & 2 & $\begin{array}{l}46 \\
16\end{array}$ \\
\hline & 4 & $\begin{array}{l}9 \\
8\end{array}$ & & $\overline{-}$ & $\begin{array}{l}3 \\
2\end{array}$ & $\begin{array}{l}16 \\
10\end{array}$ \\
\hline \multirow{4}{*}{$\begin{array}{l}\text { Total number of women } \\
\text { Action: } \\
\text { Specialist referral» } \\
\text { Return to GP } \\
\text { Reassured, no further } \\
\text { action } \\
\text { Drugs prescribed }\end{array}$} & $n=10$ & $n=73$ & Stoke & $\mathrm{n}=10$ & $\mathrm{n}=4$ & $\mathrm{n}=96$ \\
\hline & $\begin{array}{l}1 \\
1\end{array}$ & $\begin{array}{l}22 \\
29\end{array}$ & & $\begin{array}{l}8 \\
1\end{array}$ & $\begin{array}{l}2 \\
1\end{array}$ & $\begin{array}{l}33 \\
32\end{array}$ \\
\hline & 8 & 17 & & - & $\overline{1}$ & 25 \\
\hline & - & 12 & & 1 & 1 & \\
\hline
\end{tabular}

* "Specialist referral" includes direct referral for open access mammography

1 DHSS Breast cancer screening, London: HMSO, 1987.

2 Kalache A, Roberts M, Stratton I. Breast Cancer: views of general practitioners on its detection and treatment. $\mathcal{F} R$ Coll Gen Pract 1984; 34: 250-4.

3 Nichols S, Water W. Effect on doctors workload of a campaign to encourage early reporting of breast symptoms. campaign to encourage early reporting of breast sym

4 Bywaters JL. The incidence and management of female breast disease in a general practice. $\mathcal{F} R$ Coll Gen Pract 1977; 27: 353-7.

5 UK Trial of Early Detection of Breast Cancer Group. Trial of early detection of breast cancer: description of method. Br ₹ Cancer 1981; 44: 618-27.
6 Whitehead M. The Health divide: inequalities in health in the 1980's. London: Health Education Council, 1987.

7 Hobbs P, Smith A, George A, George WD, Sellwood RA. Acceptors and rejectors of an invitation to undergo breas Acceptors and rejectors of an invitho referred themselves. screening compared with those who referred them Commity Health 1980; 34: 19-22.

8 Huguley $C$, Brown $R$. The value of breast self examinations. Cancer 1981; 47: 989-95.

9 Cartwright A. Patients and their doctors: a study of general practice. London: RKP, 1967. 